\title{
Claude Pichois et Jean-Paul Avice, Baudelaire. Paris sans fin
}

\section{Mario Richter}

\section{Q OpenEdition}

1 Journals

\section{Edizione digitale}

URL: http://journals.openedition.org/studifrancesi/34972

DOI: 10.4000/studifrancesi.34972

ISSN: 2421-5856

\section{Editore}

Rosenberg \& Sellier

\section{Edizione cartacea}

Data di pubblicazione: 1 novembre 2005

Paginazione: 436

ISSN: 0039-2944

Notizia bibliografica digitale

Mario Richter, «Claude Pichois et Jean-Paul Avice, Baudelaire. Paris sans fin», Studi Francesi [Online], 146 (XLIX | II) | 2005, online dal 30 novembre 2015, consultato il 18 avril 2021. URL: http:// journals.openedition.org/studifrancesi/34972 ; DOI: https://doi.org/10.4000/studifrancesi.34972

Questo documento è stato generato automaticamente il 18 avril 2021.

\section{(c) (i) (9)}

Studi Francesi è distribuita con Licenza Creative Commons Attribuzione - Non commerciale - Non opere derivate 4.0 Internazionale. 


\title{
Claude Pichois et Jean-Paul Avice, Baudelaire. Paris sans fin
}

\author{
Mario Richter
}

\section{NOTIZIA}

Claude Pichois et JeAn-Paul avice, Baudelaire. Paris sans fin, Préface d'Yves Bonnefoy, Paris Musées/Paris Bibliothèques,2004, pp. 192.

1 In occasione della mostra Un Paris de Baudelaire. Charles Meryon, graveur, ex-marin è stato qui ripreso e in parte ampliato il volume pubblicato per un'altra precedente esposizione, quella intitolata Baudelaire-Paris del 1993. Introdotto da un bel saggio di Yves Bonnefoy (Paris en Poésie) nel quale la 'poeticità' di Parigi ci fa suggestivamente passare da Baudelaire a Rimbaud, da Apollinaire a Breton, il volume si presenta nella forma di un percorso attraverso le tappe significative della vita e della poesia parigina di Baudelaire, tappe accompagnate da una bella e istruttiva galleria di immagini fotografiche e dalla riproduzione di sette splendide acquaforti di Meryon, riprodotte e commentate con indubbia efficacia e capaci di illustrare nel modo più efficace il mondo in cui il poeta visse. 